\title{
Debates en torno a los efectos de la fertilización in vitro heteróloga en la filiación
}

\author{
Debates about the effects of heterologous in vitro fertilization on filiation
}

\author{
LISANDRA SUÁREZ FERNÁNDEZ ${ }^{* 1}$ \\ Luis PÉrez Orozco \\ Universidad de Matanzas, Cuba
}

\begin{abstract}
"Ser padre o madre es mucho más que un vínculo genético o biológico: es querer ser padre o querer ser madre."

Eleonora Lamm
\end{abstract}

\begin{abstract}
RESUMEN Los avances logrados en la Biotecnología, especialmente en el ámbito de las técnicas de reproducción humana asistida, han provocado transformaciones en la forma en que actualmente se conciben algunas instituciones jurídicas. La fertilización in vitro heteróloga de modo particular, a razón de la intervención de donantes de material genético, trastoca los fundamentos en los cuales se ha sostenido la filiación como categoría del Derecho de Familia, dando lugar a que se contemple la posibilidad de existencia de una tercera tipicidad filiatoria. Las polémicas teóricas y doctrinales que genera su implementación para los usuarios en relación a las presunciones filiatorias y la dimensión del consentimiento informado trascienden a los ordenamientos foráneos en solu-
\end{abstract}

\footnotetext{
* El presente trabajo es resultado de la actividad científica desarrollada por los autores en el marco del Grupo de Investigación: "El Derecho frente a los nuevos retos sociales", del Departamento de Derecho de la Universidad de Matanzas; 2016.

1. Lisandra Suárez Fernández es profesora universitaria auxiliar y notario público en Universidad de Matanzas, Cuba. Mail: lisisf85@gmail.com. Luis Pérez Orozco trabaja en el Departamento Legal y es profesor de Derecho de la Universidad de Matanzas "Camilo Cienfuegos", Cuba. Mail: luisperezorozco1994@gmail.com
} 
ciones diversas que son reflejadas de modo igualmente variado en el plano a jurisprudencial. Aún existen ordenamientos ajenos a estos cambios, generando una desprotección a los derechos de los sujetos involucrados en su utilización, cuestión que amerita una construcción normativa que atempere los basamentos teóricos de la filiación a la realidad social y la ciencia en evolución.

PALABRAS CLAVE fertilización in vitro heteróloga, filiación, familia.

ABSTRACT The advances achieved in Biotechnology, especially in the field of assisted human reproduction techniques, have led to changes in the way in which some legal institutions are currently conceived. Due to the intervention of donors of genetic material, heterologous in vitro fertilization overturns the foundations on which filiation has been maintained as a category of Family Law, giving rise to the possibility of a third type of filiation. The theoretical and doctrinal controversies generated for users by implementation of this technique in relation to filiatory presumptions and the dimension of informed consent transcend foreign systems in diverse solutions that are reflected in an equally varied manner in jurisprudence. Orders still exist which do not take these changes into account, generating a lack of protection of the rights of the subjects involved in their use; this situation merits the construction of norms to adapt the theoretical foundations of filiation to the reality of our society and evolving science.

KEYWORDS Heterologous in vitro fertilization, filiation, family.

\section{Introducción}

Ante la imposibilidad de obtener descendencia de manera natural, es necesario acudir al desarrollo científico y tecnológico para poder alcanzar el proyecto familiar. Con las técnicas de reproducción humana asistida pueden ser padres o madres quienes no podían, separando la reproducción humana de la sexualidad, permitiendo que modelos familiares en ascenso hoy día puedan tener descendencia. De forma general entre las principales alternativas terapéuticas para tratar la infertilidad, se ubican la inseminación artificial, la donación de ovocitos, la criopreservación de gametos y embriones, el diagnóstico genético preimplantacional, la maternidad subrogada y la fertilización in vitro ${ }^{2}$, siendo esta última en su variante heteróloga, objeto de estudio de la presente disertación, excluyendo por su carácter abarcador y controvertido las

2. En lo adelante el término será identificado con las siglas FIV. 
cuestiones asociadas al derecho a la vida del concepturus y a la fecundación postmortem ${ }^{3}$.

Sin embargo, la imposibilidad de concebir un hijo trasciende las fronteras médicas o psicológicas para convertirse en un problema social y jurídico, acarreando una serie de dificultades en el seno de la familia que está conformándose, sobre todo cuando a filiación se refiere.

La polémica desatada por la FIV en relación a la filiación no trasciende homogéneamente al ámbito normativo, resaltando un desentendimiento al respecto en varias naciones donde las porfías se han solventado en sede judicial, quedando a la espera de una interpretación tribunalicia favorable y un desarrollo progresivo en el orden social y jurídico, advirtiendo que si bien, la vía judicial pudiera funcionar como temporal solución, no ofrece-a criterio de los investigadores- un tratamiento uniforme, quebrantando en definitiva el principio de seguridad jurídica. Lo anteriormente expuesto pone en evidencia la necesidad de reestructurar el sistema jurídico en materia de filiación atendiendo los más recientes avances científicos y la reconfiguración de sus pilares teóricos.

Son precisamente tales inquietudes científicas pie forzado para el estudio a desarrollar con el objetivo de sistematizar las tendencias doctrinales, jurisprudenciales y legales respecto a la fertilización in vitro heteróloga, y su impacto en los basamentos de la filiación. A razón de lo planteado se define como problema científico de esta investigación el siguiente: La ausencia de presupuestos doctrinales, legales y jurisprudenciales en el orden sustantivo familiar que delimiten los efectos filiatorios derivados de la técnica de fertilización in vitro heteróloga impiden la protección adecuada de las relaciones paterno-filiales. No constituye pretensión hacer un estudio de Derecho Comparado, sino sistematizar los principales cambios en la filiación provocados por la FIV heteróloga desde una perspectiva integradora.

En Cuba, la temática de investigación cobra singular importancia toda vez que la nueva Constitución de la República de 2019 reconoce el ejercicio de los derechos sexuales y reproductivos y propicia la consolidación de todos los modelos familiares. La propia Carta Magna dispone el proceso a seguir con vistas a la promulgación de un Código de Familia que deberá desarrollar los postulados constitucionales y pronunciarse inevitablemente sobre las técnicas de reproducción humana asistida.

\section{Fecundación natural y técnicas médicamente asistidas de reproducción hu- mana}

La salud reproductiva está conformada por la capacidad de disfrutar una vida sexual satisfactoria y sin riesgos, la libertad para decidir fecundar o no hacerlo, cuándo y con qué frecuencia y por la procreación en sí misma, entendida esta última como una

3. En lo adelante el término será identificado con las siglas FIV. 
consecuencia y no como derecho. Esta gama de potestades lleva implícito el derecho a obtener información sobre planificación familiar, así como de los métodos para la regulación de la fecundidad y su acceso, el derecho a recibir servicios adecuados de atención de la salud que permitan embarazos y partos sin riesgos y den a las parejas las máximas posibilidades de tener hijos sanos. Todo ello se encuentra estrechamente relacionado con el ejercicio de los derechos sexuales y reproductivos que aunque comúnmente se utilizan en calidad de sinónimos, realmente no lo son ${ }^{4}$. Los investigadores son conscientes del debate sobre género que se suscita en torno a las técnicas de reproducción humana asistida, pero el mismo no será objeto de atención en el presente trabajo pues excede el marco metodológico pretendido.

La reproducción sexual consiste en el proceso creador de un nuevo organismo a partir de la combinación de material genético de dos seres de una misma especie. Como parte de esa simbiosis en los humanos ocurre la fecundación de los gametos masculino y femenino, dando lugar posteriormente al embrión. Cuando este proceso no puede llevarse a cabo de forma natural en una o varias de sus fases, se recurre a la Biotecnología, permitiendo mediante el uso de un conjunto de técnicas poner en contacto los elementos germinales del hombre y la mujer mediante la manipulación del material genético. Las distinciones y coincidencias entre ambas se aluden en la jurisprudencia colombiana cuando dice que:

"la diferencia entre la reproducción "natural" y la "artificial" consiste en que la primera se da por la cópula de los órganos sexuales masculino y femenino; mientras que en la segunda la fecundación del óvulo se hace sin unión sexual o ayuntamiento, aunque tales conceptos no son del todo precisos porque ambos procesos son biológicos y siguen las leyes naturales de la reproducción celular." 5

4. VALDÉS (2012) pp. 229-230 ; BLENGIO (2018) pp. 121-128.

5. Sentencia 6359 de 10 de mayo de 2017 de la Sala de Casación Civil de la Corte Suprema de Justicia colombiana, Disponible en: http://legal.legis.com.co/document/index?obra=jurcol\&document= jurcol_d19419719bf34f5a8863c69fdb4fb900>. [Fecha de consulta: 24 de mayo de 2018]. Al respecto, los autores explican que se han seleccionado fragmentos de Sentencias de diversos países de Iberoamérica por ser más afín cultural y jurídicamente a la sociedad y sistema legal cubanos. Estas resoluciones judiciales, a pesar de que no constituyen fuente de derecho en Cuba, son representativas de lo mejor de los pronunciamientos sobre reproducción asistida que han hecho algunos tribunales. Por tanto, se convierten en un referente casi obligado como orientador de futuras transformaciones en el ordenamiento jurídico nacional. 
Estos avances científicos y posibilidades tecnológicas generan análisis desde la Bioética, en busca de concienciar las consecuencias de estos progresos, ocasionando en la sociedad sentimientos encontrados, pues por un lado los nuevos descubrimientos actúan como mecanismos idóneos para conseguir una mejor calidad de vida, y, por otra parte, ocasionan un temor hacia lo inexplorado, debido a los efectos poco conocidos y en algunas ocasiones incontrolables aún. Su carácter pluridisciplinar, la relaciona con la Sociología, la Antropología, las ciencias biomédicas, la Ética y el Derecho. La relación entre la bioética y la ciencia jurídica está caracterizada por un permanente diálogo, por lo que estas últimas pueden integrarla en su marco de análisis, tomando como fundamento y límite, el respeto a los derechos humanos refrendados en instrumentos internacionales.

En el área propiamente de la reproducción humana asistida se ha originado un replanteamiento del fenómeno de la paternidad, primordialmente por el uso en la fecundación de material genético de terceras personas, generando un cierto grado de conflicto entre lo técnicamente posible, lo que la sociedad está dispuesta a aceptar y los valores que son necesarios tutelar jurídicamente atendiendo al interés social.

\subsection{La fertilización in vitro heteróloga: breve reseña de las cuestiones medulares}

Las técnicas de reproducción asistida serán entendidas, a los efectos de esta investigación, como los tratamientos o procedimientos que incluyen la manipulación tanto de ovocitos como de espermatozoides o embriones humanos para el logro de un embarazo. Dado el adelanto científico alcanzado en este campo, se utilizan diferentes variantes dentro de las cuales pueden mencionarse la inseminación artificial, la fecundación in vitro, y la transferencia intratubárica de gametos ${ }^{6}$. Las mismas se agrupan según la tecnología utilizada, de baja o alta complejidad, y en heterólogas u homólogas en atención al empleo o no de material genético de terceras personas?.

Dentro de las técnicas más utilizadas destaca la fertilización in vitro la cual reconoce su existencia tanto en la variante homóloga como en la heteróloga, siendo esta última controversial dado que, el material genético utilizado para lograr engendrar una nueva vida deviene de la donación de terceras personas, lo cual se devela como un verdadero reto para el Derecho de Familia.

El término in vitro, significa literalmente "en vidrio", lo cual se asocia a la cápsula de este material donde originariamente se realizaba este proceder, que por regla se efectúa de modo extracorpóreo, cuestión distintiva respecto a la inseminación artificial, pues esta última ocurre dentro del vientre materno. El procedimiento implica la fecundación del óvulo en un medio artificialmente creado; para luego proceder a la transferencia de embriones a la cavidad uterina. Su empleo en un principio se centró

6. BERNAL (2013) p. 137.

7. DORÍN y GIACCHETTA (2017) p. 9. 
en el tratamiento de la infertilidad femenina, pero su espectro fue ampliándose y se incorporó a todos aquellos casos en los que existe dificultad en el encuentro entre los espermatozoides y el óvulo ${ }^{8}$.

En ese contexto la fecundación in vitro heteróloga continúa estableciéndose generando para el gremio jurídico una realidad que debe ser objeto de un tratamiento técnico-legal adecuado. Tales aseveraciones se resumen magistralmente en una resolución judicial salvadoreña:

“algunas de esas técnicas de reproducción eran casi inimaginables hasta hace muy poco tiempo, ya que los campos de la Biomedicina, Biogenética y la Biotecnología, han tenido avances y descubrimientos científicos, que han abierto expectativas y esperanzas en el tratamiento de la esterilidad o infertilidad masculina o femenina, cuando otros métodos fueron inadecuados o ineficaces, existiendo una impostergable necesidad para que los Estados decreten leyes que regulen dicho status, ya que por lo general, los avances científicos van por delante del Derecho, retrasando su acomodación y este asincronismo entre la Ciencia y el Derecho, origina un vacío jurídico respecto de problemas concretos que lógicamente deben solucionarse jurídicamente, no pudiendo evadir o dejar a estas personas, los menores nacidos bajo estas circunstancias, en situaciones de abandono o indefensión." ${ }^{9}$

En el ámbito de la reproducción asistida ocurre la coexistencia, no siendo excluyentes entre sí, de dos tipos de relaciones: administrativas y familiares. Las primeras se constituyen entre los individuos que formen parte de algún tratamiento y el centro hospitalario que lo practica; mientras que las segundas se circunscriben a los vínculos jurídico familiares entre las personas que se benefician con el tratamiento médico.

Sobre los sujetos y parafraseando a Roca Trías ${ }^{10}$ existen como mínimo dos grupos implicados: usuarios y donantes de material genético, cuando la filiación sea la consecuencia de la utilización de gametos ajenos a los padres formales. Pese a su validez, los autores de esta disertación académica desean emplear otra nomenclatura, por entender que es más comprensible para delinear el rol de los involucrados en atención a la técnica. A partir de ello se decide distinguir entre sujetos activos, que pueden ser también denominados indistintamente, beneficiarios, usuarios o destinatarios, y

8. ENGUER y RAMÓN (2018) p. 107.

9. Recurso de apelación de la Cámara de Familia de la Sección del Centro, San Salvador, El Salvador de fecha 13 de julio de 1995. Disponible en: <http://www.jurisprudencia.gob.sv/DocumentosBoveda/ D/1/1990-1999/1995/07/6EB5.PDF>. [Fecha de consulta: 20 de mayo de 2018].

10. ROCA (2017) p.1. 
sujetos pasivos, reconocidos en las personas de los donantes, ya que en strictu sensu no realizan ningún uso o manejo de las técnicas, solo tributan a ellas, para la consecución de su fin.

En relación al equipo médico especializado a cargo de dicha técnica se sigue el criterio de no enmarcarlo en ninguna de las categorías anteriores, pues este sólo constituye un mero facilitador del procedimiento, aunque es cierto que el acto procreador deja de ser íntimo, exclusivo, personal e intransferible de la pareja, para pasar a ser un acto pluripersonal en que intervienen en condición de terceros, quedando su actuar vinculado a valoraciones éticas y profesionales referentes al Derecho Administrativo y Laboral.

Con la fecundación asistida heteróloga la causalidad biológica de la procreación no es razón suficiente para establecer entre los beneficiarios y los concebidos un vínculo jurídico de filiación. Todo ello aboca a reflexionar sobre la valía reconocida a la voluntad individual, cuestión sobre la que se reflexiona al formular que "la trascendencia de la voluntad [...] supondrá que, cuando en una misma persona no coincidan el elemento genético y el volitivo, se debe dar preponderancia al último. Se está ante nuevas realidades que importan una "desbiologización y/o desgenetización de la filiación”, y en cuya virtud el concepto de filiación gana nuevos contornos comenzándose a hablar de "parentalidad voluntaria" o "voluntad procreacional".

"Ciertamente, la ausencia de relaciones sexuales en el origen de la procreación, la intervención de terceros (incluido aquí el equipo médico) en la generación de nuevos seres humanos, la certeza sobre la procedencia de los gametos que han generado ese nuevo ser humano, la ruptura de numerosos condicionamientos puestos por la naturaleza y la biología, la conversión en posibles de supuestos imposibles, hace sólo unas décadas, han afectado directísimamente los pilares sobre los que se asienta la vigente regulación de la filiación y, más allá, los propios conceptos de filiación, paternidad y maternidad, y el papel de hombre y mujer en la procreación, todo lo cual resulta puesto en duda." ${ }^{11}$

En este ámbito el consentimiento constituye tanto requisito necesario y habilitante para la aplicación de la técnica, como fundamento para la constitución de una relación de filiación, hasta el punto de que se ha llegado a decir que "sustituye a la relación sexual como causa iuris." ${ }^{12}$ Su empleo es frecuente en el ámbito de las ciencias médicas, adoptando matices diferentes conforme a la disciplina donde opera, pero en todo caso, puede decirse que la teoría del consentimiento informado está basada en principios éticos, regulados por normas legales y ejecutadas por los galenos en el marco de la relación médico-paciente ${ }^{13}$.

11. MARTÍNEZ (2013) p.98.

12. JIMÉNEZ (2012) p.47.

13. TABOADA (2017) p.90. 
En la procreación médica asistida el consentimiento informado es la declaración de voluntad suficiente efectuada por los beneficiarios y donantes. En cuanto a los primeros, es un elemento base e integrador de la filiación y presupuesto indispensable para la práctica tendente a este tipo de fecundación; y para los segundos, el mecanismo excluyente de cualquier sujeción filiatoria con el hijo procreado con su material genético.

En esencia se trata de un acto jurídico que trasciende la esfera del documento administrativo, en tanto repercute en el ámbito del Derecho de Familia, pues la aceptación de la fecundación in vitro, es la fuente creadora del vínculo de filiación, independiente de la verdad biológica, generando un verdadero status filii, aún más, un status familiae.

Para someterse a la FIV y a cualquier tratamiento de reproducción asistida, el personal médico previamente debe observar y recabar en el documento contentivo del consentimiento informado algunos requisitos como la capacidad, el estado civil y hacer referencia al status filiatorio de la criatura que pueda concebirse. Sin embargo, la trascendencia del acto sugiere que sean operadores del Derecho, por su sapiencia en el tema, los que tramiten esta fase del procedimiento y más específicamente los Notarios. Siendo estos por envestidura de la ley funcionarios autorizantes de instrumentos que rigen las relaciones jurídicas entre las personas, y receptores de sus inquietudes sobre las relaciones de derecho que detentan o establezcan en un futuro, parece inadecuado que sea el personal médico el competente para recibir, interpretar, validar y dar certeza de esos hechos, toda vez, que su formación profesional no abarca esas aristas de la realidad ni está investido de dichas funciones.

En los casos de la fecundación asistida heteróloga, el hijo nacido como consecuencia de ella, tendrá la filiación de las personas beneficiarias de la técnica, siempre y cuando hayan prestado su consentimiento conforme a lo estipulado en el orden legal, no pudiendo impugnar la filiación legalmente determinada. La voluntad de los padres sería suficiente para bloquear el emplazamiento filial concordante con la realidad biológica de los niños concebidos. En sentido esclarecedor la Corte Suprema de Justicia de Colombia ha fundamentado que:

“(...) la realización de un tratamiento de fecundación artificial a una mujer casada está precedido de la obtención del consentimiento de su marido, manifestación que, por una parte, es el fundamento de una relación de filiación entre el hijo así concebido y el esposo de quien es su madre (...) y, por otra, impide que aquél posteriormente pueda entablar acción de impugnación de la paternidad asi determinada, pues se considera que quien así actúa con- 
tradice los parámetros de la buena fe objetiva al comportarse en forma incoherente con sus precedentes determinaciones, restricción con la cual, además, se protegen de mejor manera los intereses del menor y de la familia." ${ }^{4}$

Las brechas teóricas que la reproducción asistida heteróloga deja al descubierto la disciplina familiar y abren el camino a replantear los modelos históricos sobre los que descansa la institución de la filiación, imponiendo a tales fines una remisión a sus elementos doctrinales. Además, la familia y el interés superior del niño como bienes jurídicos a proteger llegan a confrontarse con otros como el derecho a la intimidad y el derecho a la identidad; un conflicto en el que algunos cederán frente a otros.

\section{La heterología como nudo gordiano de la reproducción asistida}

Cuando en las técnicas de reproducción humana asistida se emplea el material genético de un donante ajeno a la pareja o proyecto familiar, se habla de técnicas heterólogas. Se define como donante aquella persona que dispone de su material genético para que pueda ser utilizado en centros autorizados y bajo un control riguroso, por terceras personas cuando estas encuentran limitaciones para poder procrear de manera natural. Son donantes tanto los hombres respecto a su semen, como las mujeres que autorizan la utilización de sus óvulos ${ }^{15}$. El carácter de anónimo que requiere este acto de donación está estrechamente vinculado con el derecho a la intimidad de las personas, que como dice Albadalejo, consiste en el poder concedido a la persona sobre el conjunto de actividades que forman su círculo íntimo, poder que le permite excluir a los extraños de entrometerse en él y de darle una publicidad que no desee el interesado". ${ }^{16}$

Es la facultad que tiene cada persona de disponer de una esfera de espacio privado, el cual no puede ser invadido por terceros, y presupone que cada individuo se reserva la potestad de planificar su vida y tener los métodos y medios adecuados para poder concretar aquellas decisiones personales sobre las que sostiene el desarrollo de su personalidad. En ese mismo sentido Díaz Magrans expone que la intimidad es la esfera o conjunto de actividades de la persona que esta precisa mantener en secreto o fuera del alcance de otras personas y que como es una necesidad del individuo, el ordenamiento jurídico se ha visto compelido a brindarle protección ${ }^{17}$.

14. Sentencia de 28 de febrero de 2013 de la Sala de Casación Civil de la Corte Suprema de Justicia de Colombia. Disponible en: <https://www.icbf.gov.co/cargues/avance/docs/csj_scc_s-_28-02-2013_ [1100131100022006-00537-01]_2013.htm>. [Fecha de consulta: 19 de mayo de 2018].

15. ISLA (2014) p.38.

16. VALDÉS (2005) p.143.

17. Ídem. 
Sin embargo, en el ámbito de la FIV heteróloga, la noción de secreto no puede definirse exclusivamente en términos jurídicos, porque la decisión de comunicar o no la utilización de gametos donados depende (generalmente) de las condiciones en que la/s persona/s hayan llevado adelante el proyecto procreacional y, más específicamente, de su subjetividad durante el proceso. En definitiva, si se mantiene o no el secreto depende del proceso de subjetivación del proyecto parental ${ }^{18}$.

Sobre el manejo de la información de índole personal de los donantes, se consideran diversos bienes jurídicos como: derecho a la intimidad, derecho a la privacidad, derecho a la autodeterminación informativa, y derecho a la protección de datos personales. "El planteo del anonimato es, no obstante, objeto de importantes reflexiones en los últimos tiempos. Por un lado, ha tenido en consideración que tanto la dación de gametos, como su recepción, integrarían el ámbito de la intimidad y que, en consecuencia, debe preservarse toda intrusión que quiebre el secreto o la reserva, si se prefiere, que dadores y receptores tienen derecho a pretender. Pero por otro lado, se ha advertido que el anonimato, llevado al extremo, en vez de defender los intereses de la persona más directamente implicada -el hijo, y su derecho a la intimidad- lo que busca fundamentalmente es la realización de las apetencias y la eliminación de las responsabilidades de las restantes personas implicadas en la operación, y, en definitiva, a la instrumentalización del hijo, que puede ver cercenado su derecho a conocer quién fue su progenitor biológico, o a contar con ese dato para la defensa de intereses morales o materiales".

Al hablar de anonimato del donante, y si se deja por sentado que este no es el padre jurídico-formal del ser nacido mediante la FIV heteróloga, se debe cuestionar qué papel desempeña este sujeto en cuanto transmisor de tal herencia genética, y cuál es su relación con el así nacido.

De un resumen de los planteamientos doctrinales al respecto se pueden distinguir varios criterios. Uno maximalista, apoyado por quienes consideran que el nacido ha de conocer al donante de quien procede, y podrá reclamarle la paternidad; existiendo esta posibilidad en todos los supuestos (concepción eminentemente genetista de la filiación y de la paternidad), o limitada a determinados casos (fundamentalmente, cuando el nacido no tenga otra posibilidad de tener padre). También está la postura minimalista de quienes defienden el anonimato del donante en todo caso, considerándose que es la mejor forma de defender la ausencia de relación jurídica entre donante y nacido. Por último, se encuentra la posición ecléctica: la de los que preconi-

18. GONZÁLEZ (2016) pp. 221-227.

19. Comisión Wamock del Reino Unido. GARZÓN (2007) pp.105-106. 
zan que el nacido sólo puede conocer los datos biogenéticos del donante en cuanto transmisor de una rica herencia genética con importante repercusión en la vida y salud de aquel, datos que no se le pueden negar, bien con base en un derecho a la salud de la persona, o en un derecho a conocer la propia identidad biológica, de la que tales datos forman parte (conocido como anonimato relativo) y la perspectiva de quienes defienden el derecho a conocer la identidad personal del donante de gametos, mas sin otra consecuencia jurídica ni derechos ${ }^{20}$.

"Una actitud prudente en la cuestión, al menos por ahora, aconseja adoptar una solución intermedia: ni el anonimato impuesto a ultranza, ni la obligación legal de informar al hijo acerca de los datos del donante y la forma de su concepción. Quizás esa solución intermedia --que respetará el derecho y el deber que tienen los padres de hablar con verdad al hijo, y el derecho de éste de acceder a la información indispensable- implica la obligación del establecimiento o del facultativo de recoger y conservar todos los datos relativos al donante y de la pareja, los que deben ser secretos y sólo podrán ser exhibidos por orden judicial o a requerimientos de la pareja o del hijo, para información de éste, cuando fuese mayor de edad. Respecto del donante, en principio no sería informado de la pareja receptora, salvo conformidad expresa de ésta"21.

De tal forma es la posición intermedia la más equilibrada basada en "la existencia de donantes y, consecuentemente, la satisfacción del derecho a formar una familia, a gozar de los beneficios del progreso científico, a la vida familiar, a la igualdad, a la autonomía personal, a la libre elección del plan de vida y a la dignidad; así como el derecho del niño nacido a conocer su origen genético" ${ }^{22}$, pero sin llegar a crear vínculos filiatorios.

Aunque el Tribunal Supremo Popular de Cuba hasta el momento de la redacción de esta investigación no ha recibido casos vinculados a técnicas de reproducción asistida, sí se pueden citar algunas sentencias en materia de filiación que consiguen arrojar algunas luces sobre el tema, o al menos invitan al debate ${ }^{23}$. Dichas sentencias son soluciones casuísticas ofrecidas en recurso de casación de lo dispuesto por los diferentes Tribunales Provinciales del país, no tienen como finalidad armonizar la legislación existente a las situaciones fácticas, y por tanto no deben asumirse con carácter generalizador, en tanto esa función la cumplen las disposiciones del Consejo de Gobierno del propio órgano de justicia. La primera resolución judicial que se comen-

20. CÁRDENAS (2015) pp. 47-65.

21. Comisión Wamock del Reino Unido. GARZÓN (2007) pp.105-106.

22. RODRÍGUEZ (2015) p. 145.

23. Sobre la temática de la filiación en Cuba, y muy escuetamente sobre su relación con la reproducción asistida. PÉREZ (2011) pp. 395-440; VALDÉS (2012) pp. 216-239; VALDÉS (2017) pp. 9-23; RODRÍGUEZ (2009) pp. 5-19; MESA (1998) y MESA (2013) pp. 5-18. 
ta es la Sentencia No. 249 de 30 de junio de 2011, y de ella resalta la importancia del dictamen pericial de un equipo multidisciplinario al declarar la inexistencia de una confusión de filiación ante un caso de adopción. En esa resolución judicial destaca el hecho de que el adolescente del cual se pretendía su adopción era capaz de identificar plenamente las figuras de sus padres biológicos respecto a las de las personas que le habían proporcionado amor filial, además de desenvolverse adecuadamente como una persona de ese grupo etáreo y alcanzado los logros propios de las diferentes etapas de su vida. Cabría preguntarse si ante el supuesto de un niño producto de fecundación asistida con material genético de una tercera persona, el pronunciamiento del equipo multidisciplinario hubiera sido el mismo. ¿En una familia como la cubana, generalmente de fuertes lazos afectivos entre sus miembros, se podría convivir comunicándole al niño su origen genético? Si en el caso que resolvió el Tribunal, el menor de edad podía distinguir el rol de sus progenitores y el de quienes fungieron como padres ("personas que le habían proporcionado amor filial"), el autor de esta tesis se inclina a pensar que sí es posible en los casos de técnicas heteróloga. Sin embargo, siempre dejando claro que no existirá vínculo filiatorio con el donante de gametos ${ }^{24}$.

\section{Fundamentos de la filiación como institución del Derecho de Familia}

Según Scotti "el vocablo filiación encierra diversos significados. En una primera acepción, implica el vínculo biológico entre una persona y sus progenitores. En un segundo sentido, desde una noción jurídica, entraña la relación entre el hijo con sus padres, lo que supone el emplazamiento de una persona en un estado civil y el establecimiento de un conjunto de derechos y deberes que nacen como consecuencia." ${ }^{25}$

Su enunciación en voz de la jurisprudencia patria se resume:

"la filiación es la relación jurídica que une a ciertas personas que pueden ser progenitores o no con otras que pueden ser procreados o no y que determina en los primeros un conjunto de deberes y derechos encaminados en esencia al cuidado, protección, alimentación y educación de los últimos, [...]." ${ }^{26}$

24. Sentencia No. 249 de 30 de junio de 2011 del Tribunal Supremo Popular, Sala de lo Civil y lo Administrativo, Juez Ponente: Isabel Arredondo Suárez, Segundo Considerando, en Boletín del Tribunal Supremo Popular, La Habana, 2011, p. 219.

25. SCOTTI (2015) pp. 77-104.

26. Sentencia No 862 de 30 de diciembre de 2005 de la Sala de lo Civil y de lo Administrativo del Tribunal Supremo Popular de la República de Cuba. Vid. Boletín del Tribunal Supremo Popular de Cuba, La Habana, 2006, p.92. 
El término filiación es correlativo a las palabras paternidad y maternidad, expresiones que designan indistintamente el vínculo que une al padre o a la madre con su hijo. Las interacciones sociales que entre sus protagonistas se catalogan como relaciones paterno-filiales encaminadas a establecer y definir los vínculos entre padres e hijos, regularizando en lo jurídico, político y social parte del estado civil del procreado.

Doctrinalmente se sistematizan dos tipos de filiación: la dada por naturaleza, tendente a asegurar la identidad personal en referencia a la realidad biológica y la de tipo civil creadora de una relación jurídica de filiación entre dos personas que no son biológicamente, ni por afinidad, progenitor e hijo entre sí. Consiste en un vínculo que, sin base biológica, tiene lugar mediante un acto jurídico administrativo o judicial, creando entre los sujetos involucrados, relaciones de derechos y deberes semejantes a los existentes en la familia consanguínea.

\subsection{El sistema de presunciones de la maternidad y paternidad}

Tanto maternidad como paternidad se han entendido históricamente a partir del hecho biológico de la procreación, asumiendo este como un hecho presumible.

La maternidad ancestralmente se establece por el parto, presunción que hasta hace no mucho tiempo se consideraba iure et de iure, en función de que no había otra forma de concebir que no fuera la natural. "El principio tradicional que sigue el derecho in genus es el mater semper certa est, puesto que el parto debidamente acreditado es el hecho que atribuye de pleno derecho la maternidad. El parto sigue al vientre, partus sequitur venter, razón por la cual, la maternidad en sentido biológico es siempre cierta. Esto, [...], se sustenta en la suposición de que el parto culmina con el proceso iniciado con la fecundación del óvulo y desarrollado sin interrupción alguna." ${ }^{27}$

La paternidad, en otro sentido, se trata de un hecho que no es posible constatar por simple observación, por lo que la ley ha recurrido a las presunciones, permitiendo que por medio de antecedentes conocidos se deduzcan cuestiones desconocidas, como la paternidad. Esta se ha inferido recurrentemente de la existencia cierta del matrimonio y la maternidad, tal y como se alega al referir que "la presunción derivada del Derecho Romano consiste en reputar padre al marido de la mujer que ha dado a luz al hijo." ${ }^{28}$

Lo que hoy se conoce más brevemente como pater is est, lleva a determinar un hecho que ocurre en la privacidad y, comprende a los hijos nacidos después de la celebración del matrimonio y hasta un número de días, determinados por ley, después de decretado su disolución. El reconocimiento de paternidad es el resultado de la ma-

27. VARSI (2017) p.127.

28. DERUGGIERO (1978) p. 197. 
nifestación expresa o tácita del pretendido padre de su relación sexual con la madre en el periodo de la concepción, generando una presunción iuris tantum, sobre la que cabe prueba en contrario por conducto de las acciones filiatorias previstas por ley ${ }^{29}$.

Estas presunciones devienen en incongruentes con el advenimiento de la fecundación asistida heteróloga, pues se apoyan en una realidad biológica circunscripta al hecho de que en "las relaciones sexuales mantenidas por un hombre y una mujer es habitual que nazcan niños", y no pueden subsistir sin ella. A partir de ahí, marido y mujer tienen relaciones sexuales con el principio de exclusividad de tales relaciones, para concluir que lo normal es que los hijos de la mujer sean también (biológicamente) del marido.

29. Muy interesantes resultan dos sentencias del máximo órgano judicial cubano. En ambos casos, el Tribunal le otorgó mayor credibilidad a la prueba testifical frente a la documental que acreditaba la imposibilidad para procrear como causa para impugnar la filiación ya establecida. Sentencia No. 510 de 31 de octubre del 2013 del Tribunal Supremo Popular de la República de Cuba, Sala de lo Civil y lo Administrativo, Ponente: Isabel Arredondo Suárez, Tercer Considerando: "el impugnante sustenta la inconformidad que relata, en inequívoco criterio personal valorativo de los elementos de prueba obrantes en las actuaciones, de manera que sobreestima el resultado de las pruebas de documentos consistentes en resultas de espermograma que se le practicara por el Departamento de Biología Reproductiva del Hospital "Eusebio Hernández" y certificado médico emitido por facultativa, cuando por su contenido no resultan contundentes, en tanto no determinan su imposibilidad física para procrear, constatándose como las pruebas de testigos y de reconocimiento de personas practicada a instancia de su contraria en el pleito, aportan elementos de juicio diametralmente opuestos a los que pretende hacer valer". Sentencia No. 895 de 23 de diciembre de 2014, Ponente: Marta Acosta Ricart, Segundo Considerando: El inconforme "sostiene el infundado criterio de que se han valorado erróneamente las documentales que oportunamente presentó en relación con el resultado de un estudio que se le realizó, denominado espermograma, lo que en realidad no acontece, pues en los razonamientos en que se sustenta la decisión impugnada, si se evalúa dicho extremo, pero no se le concede virtualidad suficiente para descartar la probabilidad de la procreación, debido a la fecha posterior en que se realizó, fuera del periodo en que tuvo lugar la fecundación, pero además, porque resultaron de mayor peso y credibilidad, las pruebas de testigos y la pericial consistente en examen antropológico comparativo". 
Ello descarta el reconocimiento de la paternidad fuera del ámbito de la consanguinidad, cuestión a repensar en clave de expansión al comentar que, "a quien de manera persistente ha ostentado con firmeza y sin interrupción un comportamiento como padre, deberá serle respetada dicha posesión de estado acreditada por un tractatus y reputatio ininterrumpida en su condición o función social (...). La relación de filiación hay que disociarla de su componente genético; es o debe ser ante todo, una relación socializante, de suerte que el vínculo biológico debe quedar desnaturalizado en favor de un nexum de integración cultural." ${ }^{\circ}$

En igual línea de pensamiento resultan categóricas las palabras de Benavente Moreda quien refiriéndose al actual sistema de presunciones señala que "es evidente el conflicto que se produce y aventuro que se seguirá produciendo, derivado de la aplicación "forzada" de las citadas reglas cuando la filiación tiene su origen en el uso de dichas técnicas de reproducción asistida y básicamente en los casos de fecundación heteróloga, fundamental y básicamente porque, salvo en los casos en los que la biología manda, es la voluntad y no la biología la que determina legalmente la atribución de la paternidad o maternidad. A partir de tal dato, resulta insostenible utilizar las mismas reglas de juego," ${ }^{31}$ convocando a reelaborar las presunciones en un sentido de evolución.

\section{La fertilización in vitro heteróloga y sus efectos jurídicos en la filiación}

\subsection{El elemento subjetivo en la fertilización in vitro heteróloga}

El término sujeto de Derecho hace referencia al elemento subjetivo de una relación jurídica concreta, siendo esta última categoría "una situación en la que se encuentran dos o más personas, que aparece regulada como una unidad por el ordenamiento jurídico, organizándola con arreglo a determinados principios, y que la considera, además, como cauce idóneo para la realización de una función merecedora de la tutela jurídica." ${ }^{32}$

En el orden de los sujetos beneficiarios resalta la restricción de acceso a esta técnica de nuevas estructuras familiares, cuestión -a juicio de los autores- niega la evolución de esta institución y conlleva un cambio de ideología ${ }^{33}$. La porfía de su implementación a mujeres solteras se esclarece por parte de la Corte Interamericana de Derechos Humanos, institución que se ha pronunciado favorablemente respecto a la familia monoparental al razonar:

30. LLEDÓ (1988) pp.73-75.

31. BENAVENTE (2017) pp. 1-36.

32. VALDÉS (2005) pp.79-80.

33. FERNÁNDEZ (2016) pp. 119-146. 
"[...] la decisión de tener hijos biológicos a través del acceso a técnicas de reproducción asistida forma parte del ámbito de los derechos a la integridad personal, libertad personal y a la vida privada y familiar. Además, la forma como se construye dicha decisión es parte de la autonomía y de la identidad de una persona tanto en su dimensión individual como de pareja." ${ }^{34}$

En similar situación de inadmisión se encuentran las parejas del mismo sexo, quienes bajo juicios naturales y morales, asociados a la reproducción y la sexualidad, encuentran sólidos obstáculos para identificarse como una válida familia, con plenos derechos a realizarse como padres. Ello, como parte del reconocimiento de pluralidades familiares al margen de su orientación sexual ${ }^{35}$, el derecho a formar una familia consagrado universalmente ${ }^{36}$ y la definición amplia del derecho a la salud, debería desencadenar en una permisibilidad a las alianzas del mismo sexo de acogerse a los beneficios de la reproducción asistida, tal y como se asevera al concluir que es perentorio "plantearse alternativas que supongan una mejora para la crianza de las hijas/ os, sin distinción de la forma en la que han sido concebidos o gestados, o del tipo de familia de la que forman parte." ${ }^{37}$

Lo anteriormente expuesto conduce a abrir el horizonte en cuanto a los beneficiarios de la técnica, en tanto, su determinación no debe desligarse de los nacientes modelos familiares, que en definitiva, sólo contemplan una gama más amplia de formas de constitución de la filiación.

\subsection{El otorgamiento de la voluntad mediante el consentimiento informado: sur- gimiento de una tercera fuente de filiación}

Acorde con el principio de verdad formal, el rol jurídicamente relevante en la heterología es, por tanto, el de padre y no el de progenitor. Lo que provoca que terminológicamente se comiencen a diferenciar esos términos, atribuyéndose a la paternidad un específico contenido jurídico, sociológico y cultural. ${ }^{38}$ En relación a su jerarquía también se ha pronunciado la jurisprudencia española al colegir que si uno de los cónyuges:

34. Sentencia de 28 de noviembre de 2012 de la Corte Interamericana de Derechos Humanos, relativa al caso Artavia Murillo y otros. vs Costa Rica. Cfr. punto 272, p.86.

35. ESBORRAZ, (2015) pp. 30-31.

36. Cfr. precepto 24 de los Principios sobre la aplicación de la legislación internacional de Derechos Humanos en relación con la orientación sexual y la identidad de género, Yogyakarta, Indonesia, 2006.

37. CATALÁ (2015) p.238.

38. LAMM (2012) pp.76-91. 
“(..) tuvo la voluntad procreacional por haberse constatado que era estéril y descartado por tanto la procreación por naturaleza, aceptó la donación de semen de donante anónimo consintió el uso de la técnica que se implementó a su esposa en el momento en que tuvo lugar la concepción y por tanto debe asumir las consecuencias jurídicas de tal decisión." ${ }^{39}$

Ello sugiere que además de la filiación natural y adoptiva, se debería comenzar a concebir con mayor amplitud una tercera tipicidad, teniendo en cuenta el desarrollo de estas técnicas, su situación actual, y la imposibilidad de comprenderla en alguna de las dos clases de filiación existentes, ya que, en la derivada de las técnicas de reproducción asistida heterólogas no coincide, por la voluntaria aportación de material genético empleado en la concepción de la nueva vida, la paternidad/maternidad genética o biológica con la formal. Los autores aclaran que cualquier diferenciación en cuanto a las fuentes filiatorias debe tener carácter puramente académico y metodológico.

De la Torre explica que, a pesar de existir características compartidas entre las tres fuentes filiales, también se advierten diferencias. La práctica de la reproducción asistida heteróloga carece de la relación sexual como presupuesto inmediato, disociándose el elemento biológico, el genético y el volitivo, cobrando éste último primacía; siendo posible realizar los deseos de paternidad/maternidad ${ }^{40}$.

Tomando en líneas generales los criterios de Eleonora Lamm ${ }^{41}$, puede referirse que en la filiación por naturaleza el vínculo se funda en el elemento biológico (que comprende el genético), en la reproducción asistida heteróloga no es así y hace que sea diferente su determinación y el régimen de impugnación. En la adopción el niño ya existe cuando surge la voluntad de adoptarlo, mientras que en la FIV el elemento volitivo está presente desde el mismo origen de la persona, es decir, el niño nace y existe como consecuencia de esa voluntad.

39. Sentencia No 28 de 27 de septiembre 2007 de la Sala de lo Civil y Penal del Tribunal Supremo de Justicia de Cataluña. Disponible en: https://www.iberley.es/jurisprudencia/sentencia-civil-n28-2007-tsj-cataluna-sala-civil-penal-sec-1-rec-135-2006-27-09-2007-5733341?term=Sentencia+ Civil $+\mathrm{N} \% \mathrm{C} 2 \% \mathrm{BA}+28 \% 2 \mathrm{~F} 2007 \% 2 \mathrm{C}+$ Tribunal + Superior $+\mathrm{de}+\mathrm{Justicia}+\mathrm{de}+\mathrm{Catalu} \% \mathrm{C} 3 \% \mathrm{~B} 1 \mathrm{a} \% 2 \mathrm{C}+\mathrm{Sa}$ $\mathrm{la}+\mathrm{de}+\mathrm{lo}+\mathrm{Civil}+\mathrm{y}+$ Penal $\% 2 \mathrm{C}+$ Secci $\% \mathrm{C} 3 \% \mathrm{~B} 3 \mathrm{n}+1 \% 2 \mathrm{C}+\mathrm{Rec}+135 \% 2 \mathrm{~F} 2006+\mathrm{de}+27+\mathrm{de}+$ Septiembre + $\mathrm{de}+2007 \&$ query $=$ Sentencia + Civil $+\mathrm{N} \% \mathrm{C} 2 \% \mathrm{BA}+28 \% 2 \mathrm{~F} 2007 \% 2 \mathrm{C}+$ Tribunal + Superior $+\mathrm{de}+$ Justicia + $\mathrm{de}+$ Catalu $\% \mathrm{C} 3 \% \mathrm{~B} 1 \mathrm{a} \% 2 \mathrm{C}+\mathrm{Sala}+\mathrm{de}+\mathrm{lo}+\mathrm{Civil}+\mathrm{y}+$ Penal $\% 2 \mathrm{C}+\mathrm{Secci} \% \mathrm{C} 3 \% \mathrm{~B} 3 \mathrm{n}+1 \% 2 \mathrm{C}+\mathrm{Rec}+135 \% 2 \mathrm{~F} 20$ 06+de+27+de+Septiembre+de+2007\&noIndex. [Fecha de consulta: 23 de mayo de 2018].

40. RODRÍGUEZ et al (2017) p.7.

41. LAMM (2012) pp.87-89. 
"Cuando el nacimiento se produce mediante técnicas de reproducción asistida el principio de veracidad paterno-filial carece de toda relevancia, protegiéndose de forma lógica la estabilidad de la relación paterno-filial constituida [...] De este modo, además del orden familiar natural y de la filiación por adopción, tradicionalmente admitida en nuestro derecho, se introduce la regulación de la filiación mediante el empleo de esta ciencia separando los conceptos de progenitor y padre legal (...). Consecuencia de esta legislación es que existan dos planos de regulación de la filiación: el realista basado en el principio de veracidad que pretende la total correspondencia entre la verdad biológica y la jurídica que posibilita la investigación de la paternidad y el de la ficción legal o voluntarista que basa en la voluntad y en el consentimiento del empleo de técnicas de fecundación artificial y consecuentemente la asunción de una paternidad no biológica resultado de las técnicas, con los mismos efectos jurídicos que la filiación por naturaleza." ${ }^{42}$

\subsection{El ejercicio de la función notarial en el contexto de la reproducción asistida}

La manifestación de la voluntad para someterse a la FIV y a cualquier tratamiento de reproducción asistida es un requisito esencial respecto al despliegue de sus efectos médicos y jurídicos. Con solo hacer público el deseo de ser beneficiario de las técnicas, no es suficiente para crear una relación a la que el orden legal le otorgue tutela. En tal sentido, el elemento volitivo debe quedar registrado en un documento al que se le denomina consentimiento informado, y que generalmente es administrado por el personal médico. En ese instrumento se recaba información como la capacidad, el estado civil y el status filiatorio de la criatura que pueda concebirse.

Sin embargo, la trascendencia del acto sugiere que sean operadores del Derecho, por su sapiencia en el tema, los que tramiten esta fase del procedimiento y más específicamente los Notarios. Siendo estos por envestidura de la ley funcionarios autorizantes de instrumentos que rigen las relaciones jurídicas entre las personas, y receptores de sus inquietudes sobre las relaciones de derecho que detentan o establezcan en un futuro, parece inadecuado que sea el personal médico el competente para recibir, interpretar, validar y dar certeza de esos hechos, toda vez, que su formación profesional no abarca esas aristas de la realidad ni está investido de dichas funciones.

42. Sentencia No 44 de 22 de diciembre de 2008 de la Sala de lo Civil y Penal del Tribunal Supremo de Justicia de Cataluña. Disponible en: <https://www.iberley.es/jurisprudencia/sentencia-civil-n44-2008-tsj-cataluna-sala-civil-penal-sec-1-rec-30-2007-22-12-2008-11565341?term=Reproducci $\% \mathrm{C} 3 \% \mathrm{~B} 3 \mathrm{n}+$ asistida + Filiaci\%C3\%B3n\&query $=$ Reproducci\%C3\%B3n+asistida+Filiaci\%C3\%B3n\&no Index>. [Fecha de consulta: 23 de mayo de 2018]. 
De manera que es el Notario - a juicio de los autores- el operador del Derecho idóneo para participar en la creación del documento donde se consienta participar de la técnica de reproducción asistida con sus correspondientes consecuencias jurídicas. Con su intervención se interpreta la voluntad de las partes y adecúa la misma a las exigencias legales, dando fe de la identidad, la capacidad y la legitimación de los otorgantes en relación con el acto o negocio jurídico concreto que pretenden realizar, controlando la legalidad y asegurándose de que la voluntad de las partes sea libremente declarada.

Posee al tiempo la pericia necesaria para apreciar esa capacidad volitiva de los sujetos, que le permita autorizar el instrumento público, que en este caso en estricta técnica debe ser la escritura notarial, en tanto son el reservorio de los actos y negocios jurídicos, en el que la voluntad es presupuesto mismo de su existencia ${ }^{43}$. Como operador del Derecho, actúa con la responsabilidad que su quehacer requiere y, de manera integral, genera un medio de prueba que es plenamente válido para producir un vínculo jurídico tan relevante como lo es la filiación, gracias a su labor de información, asesoramiento y la imparcialidad, independencia, legalidad y dación de fe que ejercita con su actuar. El valor probatorio del instrumento público está dado por el principio de indubitabilidad, y contiene una presunción de autenticidad que lo legitima en el tráfico jurídico e impide que sea desvirtuado, a no ser judicialmente. Las cuestiones en debate se esclarecen magistralmente por el Tribunal Supremo de Justicia de Cataluña quien ha dicho que:

"no cabe duda que la legislación catalana exige un plus de seguridad juridica al establecer que el consentimiento del marido se preste en escritura pública. Es igualmente claro que el instrumento público garantiza en principio la libertad, la consciencia, el carácter expreso y escrito del consentimiento prestado para asumir la paternidad resultante de la inseminación. La intervención del Notario que asesora, indaga la voluntad del compareciente y comprueba la capacidad natural del otorgante, atribuye al acto una presunción de legalidad." 4

\section{PÉREZ (2014) p.168.}

44. Sentencia No 28 de 27 de septiembre 2007 de la Sala de lo Civil y Penal del Tribunal Supremo de Justicia de Cataluña. Disponible en: https://www.iberley.es/jurisprudencia/sentencia-civil-n28-2007-tsj-cataluna-sala-civil-penal-sec-1-rec-135-2006-27-09-2007-5733341?term=Sentencia+ Civil $+\mathrm{N} \% \mathrm{C} 2 \% \mathrm{BA}+28 \% 2 \mathrm{~F} 2007 \% 2 \mathrm{C}+$ Tribunal + Superior $+\mathrm{de}+$ Justicia $+\mathrm{de}+\mathrm{Catalu} \% \mathrm{C} 3 \% \mathrm{~B} 1 \mathrm{a} \% 2 \mathrm{C}+\mathrm{Sa}$ $\mathrm{la}+\mathrm{de}+\mathrm{lo}+\mathrm{Civil}+\mathrm{y}+$ Penal\%2C+Secci\%C3\%B3n+1\%2C+Rec+135\%2F2006+de+27+de+Septiembre+ $\mathrm{de}+2007 \&$ query $=$ Sentencia + Civil $+\mathrm{N} \% \mathrm{C} 2 \% \mathrm{BA}+28 \% 2 \mathrm{~F} 2007 \% 2 \mathrm{C}+$ Tribunal + Superior $+\mathrm{de}+$ Justicia +

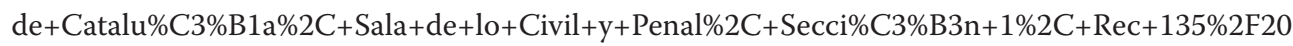
06+de+27+de+Septiembre+de+2007\&noIndex $>$. [Fecha de consulta: 23 de mayo de 2018] . 
La autenticidad que confiere la intervención del notario en los actos de los particulares y el estado en sus relaciones jurídicas, constituye un valor agregado para la prevención de litigios, siendo consustancial a su actividad, su carácter tutelar, de forma que se eviten contiendas que en algún momento pudieran generarse acerca de las instituciones familiares, especialmente la filiatoria. A diferencia del médico, tiene profesionalidad en actuaciones que se encuadren en el Derecho de Familia y que estén exentas de toda contienda o litigio lo cual "garantiza la protección de los derechos, libertades e intereses particulares en las relaciones personales, familiares, patrimoniales y extrapatrimoniales." 45

A este profesional del Derecho se le ha encomendado la misión de custodiar los intereses involucrados en los actos de los particulares en calidad de depositario de la fe del Estado; asesorando a las partes y adaptando la verdadera voluntad de estos a la ley; o sea, diseñando una forma propia de regular el acto conforme a la autonomía de la voluntad y en el marco de la ley, de manera tal que, el documento redactado se convierte en una obra de ingeniería jurídica.

De conformidad con los elementos vertidos, los autores consideran que la declaración del consentimiento informado para la aplicación de la FIV debe ser instrumentada mediante escritura pública. Así, se da una respuesta acabada a las cuestiones de lugar y fecha cierta, al momento del otorgamiento, a la conservación en el tiempo a través del sustento de la matriz del protocolo, a la capacidad del otorgante, tal como al pronunciamiento de los sujetos sobre la impugnabilidad de la filiación del niño que pueda nacer, devenido del asesoramiento integral respecto al tema, generando, además, un basamento certero a su validez probatoria en caso de conflicto sobrevenido.

\subsection{El ejercicio de acciones filiatorias a la luz de la FIV}

Estas acciones tienen por objeto obtener de los órganos jurisdiccionales competentes un pronunciamiento relativo a la filiación, ya declarándola, si no ha sido determinada de otra manera, o bien refutando la establecida formalmente. Las mismas se catalogan como acciones de estado, por cuanto, a través de ellas se persigue un pronunciamiento judicial que cree, modifique o extinga un estado de familia. Gesurmino Massaccesi citando a Belluscio expone que las mismas "son inalienables, irrenunciables, imprescriptibles e inherentes a las personas. Pueden ser: constitutivas de estado: aquellas que tienden a obtener un estado de familia nuevo o extinga o modifique el existente; declarativas de estado: se limita a reconocer una situación jurídica anteriormente existente; de reclamación: que se reconozca un estado existente o de impugnación: que se destruya un vínculo existente." ${ }^{46}$

45. DI CASTELNUOVO (2016) p.117.

46. GESURMINO (2018) p.63. 
Tanto las acciones de reclamación como las de impugnación conllevan un análisis a partir de las transformaciones operadas en la filiación, por la implementación de las nuevas técnicas de reproducción asistida. Tales razonamientos se establecen sobre la base del consentimiento prestado para la realización de ellas, donde el donante queda excluido de que se le reclame el status filii, ya que él no externa su voluntad en ese sentido, tal como de que impugnar la filiación reconocida al tercero, ya que no puede ir contra sus propios actos ${ }^{47}$.

No obstante, podría ser impugnada si se considera la existencia vicios del consentimiento al momento de otorgarlo, cuestión que comenta Guzmán Ávalos y Valdés Martínez al reseñar que "quien haya dado su consentimiento para un tratamiento de asistencia médica para la procreación no podrá impugnar la filiación, a no ser que la pretensión se base en que el hijo(a) no nació como consecuencia del tratamiento o que el consentimiento fue privado de efecto." ${ }^{48}$

Si bien es cierto, existe una aparente contraposición con respecto al anonimato del donante y al derecho a conocer el origen del niño como interés superior ${ }^{49}$, en la legislación cubana se determina el anonimato de donante como regla general. La solución adoptada es meritoria porque respeta las precauciones de anonimato que son necesarias para realizar las técnicas, pero ante un conflicto de intereses da primacía a la salud del hijo. Con lo cual, se logra un equilibrio que posibilita la continuidad de donantes y garantiza las necesidades del hijo, estableciendo que ni el anonimato es iure et de iure, ni el derecho a conocer al donante de gametos es absoluto.

Sin embargo, la regla que apunta a distanciar a donante y concebido en el orden de la filiación no impide rotundamente que existan determinados nexos entre ellos, sobre todo cuando el hijo procreado con material genético de una tercera persona desea conocer su origen. A su favor en líneas generales se afilia la Convención de Nacio-

47. Sobre la teoría de los actos propios BELLUSCIO (2004) p.266.

48. GUZMÁN y VALDÉS (2018) p.16

49. "El concepto de interés superior significa reconocerle derechos al niño en su condición de persona en desarrollo. En efecto, resultará de su interés toda acción o medida que tienda a respetar de manera efectiva sus derechos, y se constituirá en pauta de decisión ante un conflicto de intereses, y en criterio para la intervención institucional destinada a proteger al niño". MONTEJO RIVERO y HERNÁNDEZ SOSA (2011) p.83. 
nes Unidas sobre los derechos del $\mathrm{Niño}^{50}$, pese a que, el derecho a conocer el propio origen en caso de fecundación heteróloga debe matizarse con los límites que vienen dados, sobre todo, por el derecho a la intimidad del donante que quiere permanecer en el anonimato; pero también por el derecho a la intimidad personal y familiar de los padres jurídicos del hijo en el sentido de la afectación que para la convivencia familiar y la intimidad de los padres puede suponer que el hijo conozca la forma en que se ha engendrado. Pese a ello, se ha considerado que el anonimato del donante de material genético, debe ceder ante circunstancias extraordinarias como en aquellos casos en que exista peligro cierto para la vida o la salud del hijo, haber arribado el hijo a la mayoría de edad o emancipación y contar con el consentimiento del donante o por haber sido dispuesto por resolución judicial ${ }^{51}$. Sin embargo ello no genera alteración alguna en la determinación filiatoria, ni involucra acciones judiciales al respecto, quedando tales intenciones y vínculos en consensuadas relaciones privadas.

\subsection{Los efectos que origina la FIV en las relaciones paterno-filiales desde la óp- tica normativa de legislaciones latinoamericanas y europeas}

Con el afán de exponer de modo sucinto los efectos en materia filiatoria de la fecundación asistida heteróloga en ordenamientos jurídicos foráneos, y sin llegar a realizar un verdadero estudio de Derecho Comparado, se desarrolla este apartado, a los fines de valorar su factibilidad ante una posible reforma de la normativa familiar en Cuba, aunque sin ánimo de exportar modelos jurídicos. Se consideraron como parámetros de comparación: la participación de los donantes y su anonimato, beneficiarios, el sistema de presunciones, así como el consentimiento y su instrumentación.

Entre las similitudes se pueden encontrar naciones que cuentan con legislación específica de tipo administrativo o recomendaciones de tipo médico-ético, que normalmente orientan la modificación de Códigos Civiles o de Familia ${ }^{52}$, según corresponda, en lo pertinente a la institución filiatoria. Otros países como Paraguay, Colombia y

50. La Convención de Naciones Unidas sobre Derecho del Niño en su Artículo 7, apartado 1 expresa que "El niño será inscripto inmediatamente después de su nacimiento y tendrá derecho desde que nace a un nombre, a adquirir una nacionalidad y, en la medida de lo posible, a conocer a sus padres y a ser cuidado por ellos". La Convención no utiliza el término "biológicos" para referirse a los padres del niño, por tanto, no existe un derecho expreso a "conocer los padres biológicos", lo que se atempera plenamente con la realidad que implica la reproducción asistida heteróloga donde los donantes no tienen ningún vínculo parental con los procreados con su material genético.

51. CÁRDENAS (2015) pp. 47-65 ; MUÑOZ y VÍTTOLA (2017) pp.208-228.

52. Bélgica, Grecia, Holanda, Portugal, Suiza, Francia, España, Reino Unido, Italia, Austria, República Checa, Brasil, Colombia, Uruguay, Argentina. 
Venezuela abordan puntualmente la temática desde normativas sobre la niñez y adolescencia.

En la generalidad se reconoce la posibilidad de utilizar donantes de material genético cuando así se requiera, no siendo así en Italia y Noruega donde es posible únicamente el empleo de gametos provenientes de la pareja, pese a que, la jurisprudencia italiana en voz de su Tribunal Constitucional en sentencia No.162 de 2014 declaró inconstitucional la prohibición de fecundación heteróloga.

En relación al anonimato del donante se sistematizan cuatro sistemas. En uno de los extremos se encuentran aquellas legislaciones que aseguran el derecho de los niños a conocer sus orígenes al revelar la identidad del donante a toda costa, de la cual son exponentes Reino Unido, Holanda, Austria, Suecia, Suiza, Finlandia, haciendo valer el aforismo latino vincit omnia verita. En otro extremo se encuentran normas donde el anonimato es absoluto, siendo exponentes Francia y Dinamarca.

Otra forma de regulación es la denominada de "doble ventanilla", acogida por las legislaciones de Bulgaria, Bélgica, Islandia y Argentina ${ }^{53}$, permitiendo que la elección sea llevada adelante por los donantes o receptores, es decir, que la decisión escapa al niño y es tomada por los padres previo a su nacimiento.

También existe una postura ecléctica o de anonimato relativo que permite conocer la identidad del donante en determinadas circunstancias. En este sentido se inclinan las legislaciones de Portugal ${ }^{54}$, República Checa, Grecia, España ${ }^{55}$, Uruguay ${ }^{56}$ y Brasil.

53. En el caso resuelto por la Cámara Nacional de Apelaciones en lo Contencioso Administrativo Federal de Argentina, sala V, del 29 de abril de 2014, los padres de dos personas menores de edad concebidas en virtud de técnicas de reproducción humana asistida heterólogas, promovieron recurso a fin de que el Estado Nacional creara un registro con toda la información de los centros de fertilidad y bancos de gametos respecto de sus donantes. El recurso fue admitido parcialmente a fin de garantizar la posibilidad de ejercicio efectivo del derecho a la identidad reconocido en el art. 8 de la Convención sobre los Derechos del Niño, e instó al Estado a asegurar que el centro médico y/o el banco de gametos que posibilitaron la realización del tratamiento de fertilización asistida con material heterólogo respecto de la persona menor de edad que motivó el amparo, salvaguardara la información relativa a la identidad del donante en forma reservada y sin dar acceso a ella. RODRÍGUEZ (2015) pp. 159-160.

54. Cfr. artículo 15 apartados 2, 3 y 4 de la Ley № 32 de 26 de julio de 2006 sobre reproducción asistida en Portugal.

55. Cfr. artículo 5 apartado 5, tercer párrafo, de la Ley 14/2006, de 26 de mayo, sobre técnicas de reproducción humana asistida en España.

56. Cfr. artículo 21 de la Ley No 19.167 de 2013 sobre técnicas de reproducción asistida en Uruguay. 
A pesar de la multiplicidad de sistemas, todos coinciden que en ninguna circunstancia conocer la identidad del donante implicaría la creación de vínculo filiatorio con los hijos procreados mediante su material genético ${ }^{57}$. De esa forma prevalece el status filii a favor de quien otorgó su voluntad procreacional en el documento contentivo del consentimiento informado.

En el ámbito de los beneficiarios no existe consenso, advirtiéndose en naciones como Noruega y Francia la exigencia de su implementación sólo a favor de los miembros de un matrimonio heterosexual, mientras que Suecia, Italia, Chile y España ${ }^{58}$ lo extienden a las uniones de hecho. Países como Francia, Suiza e Italia ${ }^{59}$ admiten su acceso sólo para personas con problemas de esterilidad en contraposición a España, Argentina ${ }^{60}$ y Uruguay ${ }^{61}$ que asumen una postura más de avanzada y permisiva, de lo que se colige que las técnicas de reproducción humana asistida son métodos alternativos.

Sin llegar a adentrarse a fondo, en el debate iusfilosófico sobre las leyes permisivas y restrictivas, particularmente en el ámbito de la reproducción asistida heteróloga, los autores consideran que las primeras contribuyen mejor al bien común de consolidación de la familia como célula fundamental de la sociedad. La norma permisiva, como su nombre lo indica, es la que permite, concede o autoriza hacer o no hacer algo, realiza una acción o una abstención, debiendo el otro sujeto o los otros sujetos tolerar que la persona beneficiada con el permiso haga o no haga lo que expresamente se le ha permitido. La imperatividad de la norma permisiva estaría, pues, en la imposición

57. "La acción de reclamación o de investigación de la paternidad se orienta a constituir, entre los sujetos afectados, un vínculo jurídico comprensivo de derechos y obligaciones recíprocos, integrante de la denominada relación paterno-filial, siendo así que la revelación de la identidad de quien es progenitor a través de las técnicas de procreación artificial no se ordena en modo alguno a la constitución de tal vínculo jurídico, sino a una mera determinación identificativa del sujeto donante de los gametos origen de la generación, lo que sitúa la eventual reclamación, con este concreto y limitado alcance, en un ámbito distinto." Tribunal Constitucional de España, Sentencia No. 116 del 17 de junio de 1999 en BARBER (2010), p. 34.

58. Cfr. artículo 3 apartado 1 y artículo 6 apartado 1, de la Ley 14/2006, de 26 de mayo, sobre técnicas de reproducción humana asistida en España.

59. La jurisprudencia italiana con una decisión innovadora, ha admitido la posibilidad de utilización de la reproducción artificial a una pareja, cuyos miembros no eran ni estériles ni infértiles, pero que, no obstante, eran portadores sanos de enfermedad trasmisible genéticamente al hijo. A pesar de la norma, el Juez realizó una lectura constitucional de la Ley y dedujo el derecho de los padres a tener un hijo que no estuviera afectado por esta enfermedad y de autodeterminarse en las elecciones atinentes a la esfera de la procreación. BERTI (2015) pp. 761-776.

60. Cfr. artículo 8 de la Ley No 26.862 de 2013 sobre técnicas de reproducción asistida en Argentina.

61. Cfr. artículo 2 de la Ley No 19.167 de 2013 sobre técnicas de reproducción asistida en Uruguay. 
a los sujetos pasivos de tolerar una acción u omisión de otra persona, por lo que devienen en disposiciones más incluyentes a la vez que provee una mayor protección a los más vulnerables o en riesgo de exclusión social ${ }^{62}$.

Refiriéndose a las leyes permisivas Schwember expresa que "son esenciales para el derecho privado $y$, en realidad, lo constituyen, pues prácticamente todas las normas de derecho privado son leyes permisivas o descansan o remiten a leyes permisivas. Las leyes sobre los bienes, las leyes sobre familia y las leyes sobre contratos, que constituyen el núcleo del derecho privado, descansan, en último término, en la suposición de que estamos autorizados, bajo ciertas condiciones, para realizar según nuestro arbitrio ciertas cosas que son relevantes jurídicamente y que, por lo mismo, el derecho reconoce y ampara". ${ }^{3}$

A pesar de la permisividad, se ha establecido como regla que la filiación de los hijos nacidos mediante técnicas de reproducción humana asistida se determina por el consentimiento previo, informado y libre de quienes se someten a esta técnicas, con independencia de quién hubiera aportado los gametos, regla que se reproduce en las distintas normas que regulan la determinación de la filiación (matrimonial y extramatrimonial) y subyace en la legislación de las acciones de filiación, cuando se dispone la improcedencia de la acción de reclamación y se desestima la posibilidad de desplazar la filiación en los casos de fertilización "heteróloga", si ha mediado consentimiento previo e informado de quien asumió la maternidad o paternidad ${ }^{64}$.

En cuanto a las presunciones existe una generalización de establecer un rango de tiempo (30o días) para presumir la filiación de un hijo después de extinguido el vínculo matrimonial. Sin embargo, esta figura no se ajusta a la realidad biológica y científica que caracteriza a la FIV sea homóloga o heteróloga. Se ha podido observar que en este procedimiento médico es muy frecuente que el nacimiento fruto de métodos artificiales se produzca como resultado de una gestación inferior a 180 o superior a 300 días. Si se aplicara en forma tan estricta dicho mecanismo de presunción, podría pensarse que en la mayoría de los casos de reproducción asistida que terminan satisfactoriamente, es decir con el nacimiento de un nuevo ser, pero que no se produjo dentro del término establecido, daría lugar a que el marido de la mujer impugnara su paternidad, por la simple y única razón de que el nacimiento fue extemporáneo; dejándose de lado la realidad biológica en éste tipo de procedimientos ${ }^{65}$.

62. Cfr. ISLER (2010) pp. 147-162.

63. SCHWEMBER (2014) p. 397.

64. Cfr. artículo 8 apartado 1 de la Ley 14/2006, de 26 de mayo, sobre técnicas de reproducción humana asistida en España.

65. GESURMINO (2018) p.47. 
Muy asociado a ello está la superación de los límites naturales de la procreación, propiciada por la posibilidad de conservación de embriones congelados ${ }^{66}$, que hacen, por ejemplo, que los tiempos de un embarazo normal puedan verse superados, y desde la concepción en el laboratorio hasta el nacimiento puede llegar a tardar mucho más tiempo que el establecido por la presunción. Únicamente el Código Civil argentino establece una solución salomónica al respecto, pues excluye esta presunción del ámbito de las técnicas de reproducción humana asistida ${ }^{67}$.

De las legislaciones consultadas, solo Francia y Argentina ${ }^{68}$ requieren la instrumentación del consentimiento mediante la protocolización ante Notario o Escribano público. Así el Código civil francés dispone que los cónyuges o la pareja de hecho que recurran a un donante deberán dar su consentimiento al juez o notario ${ }^{69}$.

A continuación, se explica la forma en que legislativamente se ha regulado la reproducción asistida en Códigos de Familia. Los autores de esta investigación han decidido deslindar este análisis del resto de normas jurídicas que previamente se expusieron, teniendo en cuenta que en Cuba el Derecho familiar se ha codificado de manera autónoma. Fueron considerados los Códigos de Bulgaria, Costa Rica, Bolivia, Panamá y los Estados mexicanos Sonora, Michoacán de Ocampo, Morelos y San Luis Potosí, pero se citan aquellos preceptos representativos para evitar reiteraciones innecesarias.

66. En el caso Evans contra el Reino Unido (asunto 6339/05, Sec. $4^{\text {a }}$ de 7 de marzo de 2006, confirmado Gran Sala 10 de abril de 2007) dos ex convivientes litigaron respecto a los embriones que habían sido conservados durante su relación de pareja y que se destinarían a su posterior implantación en la mujer. Luego a ella le fueron extirpados los ovarios por una enfermedad y solicitó que los embriones pudieran ser implantados con el argumento de que constituían su última oportunidad de tener un hijo genético. El hombre, por su parte, se opuso a la petición de la mujer, con el argumento de que no podía ser forzado a procrear. Ante tal situación, el Tribunal Europeo de Derechos Humanos declara que se afecta el derecho al respeto de la vida privada del demandante, un concepto amplio que comprende la decisión de ser o no padre. El Tribunal basándose en la normativa británica declaró que sí era posible que cualquier parte revocara su consentimiento al tratamiento en cualquier momento previo a la implantación del embrión. FARNÓS (2016) pp. 93-111.

67. Cfr. artículo 565 del Código Civil y Comercial de la Nación Argentina modificado en el 2014.

68. Cfr. artículo 566 del Código Civil y Comercial de la Nación Argentina modificado en el 2014 y artículo 2 de la Ley № 26.862 de 2013 sobre técnicas de reproducción asistida en Argentina.

69. Cfr. artículo 311-20, párrafo primero del Código Civil francés, modificado por la Ley No 94-653, de 29 de junio de 1994, Sección III De la asistencia médica a la reproducción. 
En los Códigos examinados existe consenso en admitir solo la práctica de técnicas de reproducción humana asistida en personas casadas o en los casos de uniones de hecho, siempre heterosexuales. No se permite el uso alternativo de estas técnicas, por lo que otros modelos familiares están vedados de acceder a ellas ${ }^{70}$. Los donantes de material genético no adquieren derechos de ningún tipo respecto al hijo procreado ${ }^{71}$.

En cuanto al sistema de presunciones solo el código búlgaro presenta novedades al regular que madre es quien da a luz, de ese modo la presunción de maternidad queda fundamentada en el hecho del parto y no en el de la concepción ${ }^{72}$. En los casos que se haya dado el consentimiento este funcionará como presunción de filiación y mediante ficción jurídica será semejante a la cohabitación para efectos de la paternidad. Se hace la salvedad de que en la reproducción asistida no podrá alegarse la imposibilidad de procreación para impugnar el status filii ${ }^{73}$.

En ese mismo sentido todos los Códigos concuerdan en establecer al consentimiento informado como base para el establecimiento del vínculo filiatorio entre el hijo procreado mediante técnicas de reproducción humana asistiday los sujetos que expresaron su voluntad procreacional ${ }^{74}$. En lo que se refiere a la intervención notarial solo se pronuncia el Código del Estado de Sonora al señalar que "la autorización de los cónyuges para recurrir a la reproducción asistida, admitiendo la paternidad o maternidad del producto, deberá hacerse ante el Director de la Clínica o Centro Hospitalario, ante notario público o por acuerdo privado suscrito ante testigos", para dejar constancia de esta nueva fuente de la paternidad o la maternidad ${ }^{75}$.

Las normas sustantivas familiares de Bolivia y del Estado mexicano San Luis Potosí tienen preceptos sui géneris en relación con las otras legislaciones de su tipo. El Código de las Familias boliviano impide establecer vínculo conyugal, entre la madre o el padre, con la hija o hijo nacida o nacido, mediante técnicas de reproducción

70. Cfr. artículos 149 Código Familiar para el Estado de Michoacán de Ocampo última reforma publicada en el periódico oficial del Estado, el 12 de abril de 2017, Tomo: CLXVII, número: 5, octava sección.

71. Cfr. artículo 207 del Código de Familia del Estado de Sonora.

72. Cfr. Código de Familia de Bulgaria de 1 de octubre de 2009, artículos 60 apartados 2 y 5, 61, 62 apartado 5 .

73. Cfr. artículo 72 último párrafo de la Ley No. 5476 de 7 de noviembre de 1973 Código de Familia de Costa Rica.

74. Cfr. artículo 244 del Código Familiar para el Estado de San Luis Potosí última reforma publicada en el periódico oficial el 17 de septiembre de 2015.

75. Cfr. artículo 208 del Código de Familia del Estado de Sonora. 
asistida con gametos ajenos ${ }^{76}$. Por su parte el ordenamiento familiar de San Luis Potosí es bastante minucioso al regular esta temática ${ }^{77}$, especificidades que a juicio de los autores resultan más apropiadas de una ley especial que de una codificación en materia de familia.

A grandes rasgos, y luego de analizar el comportamiento de las legislaciones foráneas, los autores determinan que cualquier análisis de una regulación en Cuba de las técnicas de reproducción asistida, comienza con la inevitable promulgación de una norma jurídica especial que reglamente e integre el conjunto de dichas técnicas y sus efectos. No es suficiente con Resoluciones del Ministerio de Salud Pública con tal propósito. Una norma que ampare con fundamentos bioéticos, aquellos aspectos que exceden el ámbito de la filiación, tales como: los derechos y deberes de los sujetos beneficiarios y de los donantes, las responsabilidades de las instituciones o centros de salud, el rol de los comités de bioética, el estatuto del embrión y todo cuanto le concierne en el marco de la fertilización in vitro.

Esa futura legislación especial debería estar fundamentada en la posibilidad que actualmente la Constitución da al reconocimiento de los modelos de familia, para que así el procedimiento médico de fertilización in vitro permita a todas las tipicidades acceder a él. Particularmente en los casos de parejas del mismo sexo y maternidad en solitario por elección, la fertilización in vitro se presenta de facto como una de las alternativas para alcanzar la casi siempre ansiada descendencia. De ahí que, en un país como Cuba, con vocación humanista y alto nivel de desarrollo y accesibilidad del sistema de salud, las técnicas de reproducción asistida sean legitimadas como forma alternativa de alcanzar el proyecto familiar.

Los problemas que surgen del uso de las técnicas no se identifican con las otras formas de filiación, en particular cuando se utiliza material genético externo al proyecto familiar, sea de un donante anónimo o no. El Código de Familia debería regular en una Sección denominada "De la Reproducción Asistida", los efectos de un tercer tipo de filiación: la inducida o por voluntad procreacional, como quiera nombrársele, pero sin llegar a la taxatividad. Cualquier enumeración de las tipicidades de filiación devendría inconstitucional según el Artículo 83 de la Ley de leyes. En esa Sección dedicada a este tipo filial uno de sus pilares debería ser el consentimiento otorgado de forma previa, informada y libre, pues constituye el núcleo duro del régimen filial derivado de la reproducción asistida: la voluntad procreacional.

\footnotetext{
76. Cfr. artículo 144, apartado I, inciso e de la Ley No. 603 de 19 de noviembre de 2014 Código de las Familias y del Proceso Familiar de Bolivia.

77. Cfr. artículos del 236 al 239 del Código Familiar para el Estado de San Luis Potosí última reforma publicada en el periódico oficial el 17 de septiembre de 2015.
} 
Además, ese consentimiento debe recabarse por el centro hospitalario y protocolizado por el Notario, así como ser renovado antes de iniciar cada tratamiento. Es así, que el notario cubano se convierte en un agente colaborador eficiente del logro de seguridad jurídica a las partes que ante él acuden. El notario certifica o da fe de que hay legitimidad en el derecho que se ejerce, legalidad en el acto de voluntad, licitud en los hechos observados, capacidad en los sujetos que pretenden beneficiarse de la fertilización in vitro, idoneidad en el objeto materia del acto, de que se tiene o no un régimen conyugal, se otorga una voluntad verdadera e identidad de los sujetos que actúan e intervienen.

En Cuba ya se tiene experiencia de la participación notarial en asuntos médicos. La donación de órganos y tejidos, actualmente requiere su formalización mediante escritura pública notarial ${ }^{78}$, haciendo más arduo y delicado el quehacer de este funcionario. "La atribución al notario, cada día, de nuevas competencias por razón de la materia es viva expresión de la confianza que depositan las instituciones públicas, estatales y gubernamentales en el cometido que le viene dado por ley (...). Las autoridades gubernativas recaban la presencia notarial. Confían en la mesura y prudencia de su actuar, en el cavere, en ese perfil de la labor del notario, dirigido esencialmente a la prevención (...). Nuevamente resulta la pieza clave en la seguridad jurídica preventiva que reclama un Estado de derecho. Se acude a él por la confianza que éste deposita, por su solvencia intelectual, por su probidad y por ser baluarte de la legalidad en todo acto jurídico en el que interviene. Los ojos del notario lo ven a él mismo y a los de cada miembro de la sociedad en donde se desenvuelve y por la cual ha nacido la institución que representa." 79

Por otra parte, el sistema actual de presunciones para atribuir la maternidad y la paternidad no puede ser aplicable a la reproducción asistida, pues se sustenta en el hecho biológico de la relación sexual y la cohabitación, por tanto, de mantenerse su redacción actual se tendría que dejar claro su excepcionalidad en la fecundación asistida heteróloga. La legislación especial debe establecer el periodo de tiempo en que los embriones pueden estar en conservación porque de ello dependerá la futura validez de la presunción matrimonial del Artículo 74 incisos a y b.

\footnotetext{
78. Cfr. artículos 4 y 15 de la Resolución No. 857 de 2015 del Ministerio de Salud Pública, e Indicación Metodológica No. 5 de 2015 a todos los Notarios del país por conducto de los Jefes de Departamentos o secciones de notarías provinciales, del municipio especial Isla de la Juventud, y de los Directores generales de Consultoría Jurídica Internacional, Bufete Internacional, CONABI, LEX, y la notaría adscrita al MINJUS.
}

79. PÉREZ (2015) pp.201-202. 
En interés a la relación familiar en la que queda insertado el hijo, se hace merecedor de una efectiva protección, la cual debe materializarse en la limitación de la investigación de la paternidad o maternidad genéticas, con la intención de que se le imputen así al donante obligaciones o responsabilidades paterno-filiales por el mero hecho de ser progenitor, y considerarse preferente el mantenimiento de la relación familiar en que formalmente queda insertado el hijo. La revelación identidad del donante de material genético no conllevará en ningún caso el establecimiento del status filii hacia él. Su publicidad estará supeditada a un interés superior previamente apreciado por autoridad competente.

Por último, cabe destacar otra consecuencia inexcusable y propia de la filiación derivada de fecundación asistida heteróloga, inherente al consentimiento como exteriorización de la voluntad procreacional, el autor se refiere a la imposibilidad de interponer acción de impugnación cuando se trata de filiación por esta técnica y se ha prestado el debido consentimiento informado, según los requisitos que serán fijados por la ley especial. Así lo hace el Code catalán: "Si la filiación se deriva de la fecundación asistida de la madre, la acción de impugnación no puede prosperar si la persona cuya paternidad o maternidad se impugna consintió la fecundación, y tampoco, en ningún caso, si es progenitor biológico del hijo". ${ }^{\circ}$

Ese consentimiento solo podría ser rebatido cuando se evidenciase alguno de los supuestos de ineficacia del acto jurídico que establece el Código Civil en su Título IV, Capítulo III, Sección Quinta. De conformidad con ese precepto, la imposibilidad de impugnar la filiación fundamentándose en la imposibilidad de procrear del Artículo 78 no es causa coherente para los casos de reproducción asistida.

En resumen, los autores reconocen que es necesaria una mención a la fertilización in vitro heteróloga en el Código, aunque también debería existir un precepto que permita incluir otras técnicas que el propio desarrollo de la Biotecnología pueda alcanzar.

\section{Conclusiones}

- Entre los sujetos beneficiarios de la fertilización in vitro heteróloga deberían ser incluidos otros modelos familiares, pues los mismos son parte de la realidad social, y en ocasiones quedan excluidos de dicho tratamiento. La fecundación asistida heteróloga da lugar al surgimiento de una tercera tipicidad de filiación: la voluntad procreacional, que se diferencia de la originada por naturaleza y adopción. El otorgamiento de esa voluntad debe hacerse siguiendo determinados requisitos para evitar que el

80. Cfr. artículo 235-27 apartado 2 de Ley 25/2010, de 29 de julio, Libro Segundo del Código civil de Cataluña relativo a la persona y la familia, BOE No. 203, 21 de agosto de 2010 Sección I, p. 73429 
documento que la contenga sea refutado. En este sentido la participación del Notario o Escribano Público, según sea conocido en cada país, resulta de extrema importancia pues es el funcionario por excelencia para intervenir en este procedimiento. Los pronunciamientos que las personas involucradas hagan sobre esta última, determina la existencia de derechos, deberes y facultades, incluyendo la imposibilidad de impugnar la filiación ya establecida por esta vía.

- Además, se debe preservar el anonimato del donante y este solo podrá ser develado mientras sea excepcionalmente permitido. El ejercicio de acciones filiatorias podría ser viable en los casos en que el documento que contiene el consentimiento carezca de los requisitos legalmente exigidos. A propósito, el sistema de presunciones sustentado en el hecho de la concepción resulta caduco, pues desde ese momento y hasta la implantación del embrión puede transcurrir un tiempo considerable según sea dispuesto por ley o acordado por voluntad de las personas beneficiarias.

- La regulación de las técnicas de reproducción humana asistida no es uniforme en los ordenamientos jurídicos universales, encontrando posiciones que marchan desde las más tradicionales o restrictivas hasta las miradas y enfoques más contemporáneos y audaces. Estas últimas ofrecen un reconocimiento loable a los efectos diversos que en las relaciones paterno-filiales provoca la fertilización in vitro heteróloga por lo que puede afirmarse que existe un tratamiento normativo heterogéneo. Las legislaciones foráneas sirven de orientación a las futuras modificaciones que deberá hacer el legislador del Código de las Familias cubano.

\section{Referencias bibliográficas}

BARBER CÁRCAMO, Roncesvalles (2010): "Reproducción asistida y determinación de la filiación”. En REDUR, No 8, 2010, pp. 25-37.

BELLUSCIO, Augusto César (2004): Manual de Derecho de Familia. (Buenos Aires, Editorial Astrea, Tomo II, Séptima Edición actualizada y ampliada).

BERNAL CRESPO, Julia Sandra (2013): "Reproducción asistida y filiación. Tres casos". En Opinión Jurídica, vol. 12, No 24, pp.135-150.

BERTI DE MARINIS, Giovanni (2015): "La jurisprudencia italiana en materia de reproducción asistida”. En Actualidad Jurídica Iberoamericana, № 2, pp. 761-776.

BENAVENTE MOREDA, Pilar (2017): "Los errores de legislar en paralelo: la problemática aplicación de las reglas sobre filiación (determinación, acciones de reclamación e impugnación) en la filiación derivada del uso de técnicas de reproducción humana asistida”. En Oñati Socio-legal Series, vol. 7, No 1, pp. 1-36.

BLENGIO VALDÉS, Mariana (2018): "Principio de progresividad en relación al derecho a la salud y sus consideraciones desde la ética y el derecho". En Revista de Derecho Público, Año 27, No 54, pp. 121-128. 
CÁRDENAS KRENZ, Ronald (2015): "El derecho a la identidad biológica de las personas nacidas mediante reproducción asistida en la doctrina, jurisprudencia y legislación peruana". En Persona y Familia, Revista del Instituto de la familia, vol. 1, $\mathrm{N}^{\circ} 4$, pp. 47-65.

CATALÁ PÉREZ, Consuelo (2015): "La maternización de la sociedad: derechos reproductivos y salud primal". En Revista Dilemata, año 7, No 18, pp. 225-240.

DERUGGIERO, Roberto (1978): Instituciones de derecho civil (Madrid, Instituto Editorial Reus S.A, tomo II, volumen II).

DI CASTELNUOVO, Franco (2016): "La tridimensionalidad del fenómeno notarial en materia de familia". En Revista Notarial, No 94, pp.31-204.

DORÍN, Giselle y GIACCHETTA, Paula Jimena (2017): "La Biotecnología aplicada a la reproducción humana y su influencia en las relaciones filiales". Disponible en: <http://www.derecho.uba.ar/institucional/deinteres/ponencias-congreso-derecho-privado/familia-y-sucesiones-paula-giacchetta-noelia-giselle-dorin.pdf $>$. [Fecha de consulta: 17 de diciembre de 2017].

ENGUER GOSÁLBEZ, Pablo y RAMÓN FERNÁNDEZ, Francisca (2018): "Dilemas bioéticos y jurídicos de la reproducción asistida en la sociedad actual en España". En Revista Latinoamericana de Bioética, vol. 18, № 1, pp.104-135.

ESBORRAZ, David Fabio (2015): "El concepto constitucional de familia en América Latina. Tendencias y proyecciones". En Revista de Derecho Privado, No 29, pp. 1555 .

FARNÓS AMORÓS, Esther (2016): "La reproducción asistida ante el Tribunal Europeo de Derechos Humanos: De Evans c. Reino Unido a Parrillo c. Italia". En Revista Bioética y Derecho, No 36, pp. 93-111.

FERNÁNDEZ JIMENO, Natalia (2016): "Desafiando la institución de la maternidad: reapropiaciones subversivas de tecnologías de reproducción asistida". En Revista CTS, vol. 11, № 31, pp. 119-146.

GARZÓN JIMÉNEZ, Roberto (2007): "Reproducción asistida". En Revista Mexicana de Derecho, No. 9, pp. 97-116.

GESURMINO MASSACCESI, María de los Ángeles (2018): "Las técnicas de reproducción humana asistida y las relaciones de familia". Disponible en: <https://repositorio.uesiglo21.edu.ar/bitstream/handle/ues21/11982/Tesis_T\%C3\%A9cnicas_ de_Reproducci\% $\mathrm{C}_{3} \%$ B3n_Asistidaa.pdf?sequence=1>. [Fecha de consulta: 20 de marzo de 2018].

GONZÁLEZ, Ana Cecilia (2016): “Técnicas de reproducción humana asistida heterólogas: el derecho a conocer los orígenes. ¿legislación versus subjetividad?”. En Acta Bioethica, vol. 22, № 1, pp. 221-227. 
GUZMÁN ÁVALOS, Aníbal y VALDÉS MARTÍNEZ, María del Carmen (2018) "Voluntad procreacional”. Disponible en: <http://www.colectivoderechofamilia.com/ wp-content/uploads/2015/o4/Avalos-y-Valdes-Voluntad-procreacional.pdf $>$. [Fecha de consulta: 20 de marzo de 2018].

ISLER SOTO, Carlos (2010): “Es el derecho un sistema de mandatos? La crítica de Hart a la teoría imperativista del derecho". En Revista de Derecho Universidad Católica del Norte, año 17, No 1, pp. 147-162

JIMÉNEZ MUÑOZ, Francisco Javier (2012): La reproducción asistida y su régimen jurídico (Madrid, Editorial Reus).

LAMM, Eleonora (2012): "La importancia de la voluntad procreacional en la nueva categoría de filiación derivada de las técnicas de reproducción asistida". En Revista Bioética y Derecho, No 24, pp.76-91.

LLEDÓ YAGÜE, Francisco (1988): Fecundación artificial y derecho (Madrid, Editorial Tecnos S. A.).

MARTÍNEZ DE AGUIRRE ALDAZ, Carlos (2013): "La filiación, entre Biología y Derecho”. En Prudentia Iuris, No 76, p.117-133.

MESA CASTILLO, Olga (2013): "La experiencia de una justicia familiar en Cuba: validación de la naturaleza social y el enfoque interdisciplinario del Derecho de Familia". En Revista Cubana de Derecho, IV Época, No 41, pp. 5-18.

MESA CASTILlO, Olga; et. al. (1998): Temas de Derecho de Familia, (La Habana, 1998).

MONTEJO RIVERO, Jetzabel M. y HERNÁNDEZ SOSA, Luz M. (2011): “Aproximación a la definición de interés superior del niño". En Justicia y Derecho Revista del Tribunal Supremo Popular de la República de Cuba, año 9, No. 16, pp. 82-87.

MUÑOZ GENESTOUX, Rosalía y VÍTTOLA, Leonardo Raúl (2017): “El derecho a conocer el origen genético de las personas nacidas mediante técnicas de reproducción humana asistida con donante anónimo". En IUS Revista del Instituto de Ciencias Jurídicas de Puebla, México, vol. 11, No 39, pp.208-228.

PÉREZ GALLARDO, Leonardo Bernardino (2015): “Dación de órganos y tejidos humanos entre vivos y función notarial". En IUS Revista del Instituto de Ciencias Jurídicas de Puebla, México, Nueva Época, No. 36, pp. 179-202.

PÉREZ GALLARDO, Leonardo Bernardino (2014): "Diez interrogantes sobre el juicio notarial de capacidad: Un intento de posibles respuestas". En Revista de Derecho, No 17, pp.153-183.

PÉREZ GALLARDO, Leonardo Bernardino (2011): “Luces y sombras en torno a la regulación jurídica de la filiación en Cuba". En Revista Universitas, No 122, pp. 395-440. 
ROCA TRÍAS, Encarna (2017): Filiación asistida y protección de derechos fundamentales. Disponible en: <http://www.ajs.es/downloads/volo701.pdf>. [Fecha de conSulta: 17 de diciembre de 2017].

RODRÍGUEZ CORRÍA, Reinerio (2009): "La filiación y sus acciones. Algunas reflexiones sobre su regulación y aplicación práctica". En Revista Cubana de Derecho, IV Época, No 34 , pp. 5-19.

RODRÍGUEZ ITURBURU, Mariana (2015): “La regulación de las técnicas de reproducción humana asistida en la actualidad". En Reproducción, vol. 30, No 4, pp. 143-160

RODRÍGUEZ ITURBURU, Mariana; SALITURI AMEZCUA, María Martina y VÁZQUEZ ACATTO, Mariana (2017): "La regulación de la filiación derivada de las técnicas de reproducción asistida en la Argentina: voluntad procreacional y consentimiento informado". En IUS Revista del Instituto de Ciencias Jurídicas de Puebla, México, vol. 11, No 39, pp.1-31.

SCHWEMBER AUGIER, Felipe (2014): "Lex permissiva” o contrato: crítica a la lectura rawlsiana de la doctrina del derecho de Kant". En Revista de Estudios HistóricoJurídicos, $\mathrm{N}^{\circ}$ 36, pp. 385-409

TABOADA LUGO, Noel (2017): “El consentimiento informado en la práctica asistencial e investigativa de la Genética Clínica”. En Revista Acta Médica del Centro, vol. $11, \mathrm{~N}^{\circ} 3$, pp.88-100.

SCOTTI, Luciana Beatriz (2015): “La filiación internacional en el nuevo Código Civil y Comercial de la República Argentina”. En Ars Iuris Salmanticensis, vol. 3, pp. 77-104.

VALDÉS DÍAZ, Caridad del Carmen (2005): "La relación jurídica civil. Concepto y contenido". En VALDÉS DÍAZ, Caridad del Carmen. Derecho Civil Parte general (La Habana, Editorial Félix Varela), pp.77-99.

VALDÉS DÍAZ, Caridad del Carmen (2012): "Del derecho a la vida y los derechos sexuales y reproductivos, ¿configuración armónica o lucha de contrarios?”. En IUSRevista del Instituto de Ciencias Jurídicas de Puebla, México, Nueva Época, № 29, pp. 216-239.

VALDÉS DÍAZ, Caridad del Carmen (2017): "El acceso a algunas técnicas de reproducción humana asistida: Crónica de una vida anunciada”. En Revista del Instituto de Ciencias Jurídicas de Puebla IUS, Nueva Época, vol. 11, No 39, pp. 9-23.

VARSI ROSPIGLIOSI, Enrique (2017): “Determinación de la filiación en la procreación asistida”. En IUS Revista del Instituto de Ciencias Jurídicas de Puebla, México, nueva época, año 11, No 39, pp.9-23. 


\section{Jurisprudencia citada}

Artavia Murillo y otros. vs Costa Rica (2012): Corte Interamericana de Derechos Humanos, Sentencia de 28 de noviembre de 2012.

Cámara de Familia de la Sección del centro, San Salvador, El Salvador, 13 de julio de 1995, (recurso de apelación). Disponible en: <http://www.jurisprudencia.gob.sv/ DocumentosBoveda/D/1/1990-1999/1995/07/6EB5.PDF>. [Fecha de consulta: 20 de mayo de 2018].

Corte Constitucional de Colombia, Sentencia T-1104 de 23 de agosto de 20oo. En PABÓN MANTILLAet al (2017): "El acceso a las técnicas de reproducción asistida como una garantía de los derechos sexuales y reproductivos: la jurisprudencia de la Corte Constitucional a la luz del Derecho Internacional de los Derechos Humanos". En Justicia, Universidad Simón Bolívar, Barranquilla, Colombia, No 31, Enero - Junio de 2017, pp. 171-187

Corte Suprema de Justicia de Colombia, Sala de Casación Civil, Sentencia de 28 de febrero de 2013.Disponible: https://www.icbf.gov.co/cargues/avance/docs/csj_ SCC_S-_28-02-2013_[1100131100022006-00537-01]_2013.htm. [Fecha de consulta: 17 de mayo de 2018].

Corte Suprema de Justicia Colombia, Sala de Casación Civil, Sentencia 6359 de 10 de mayo de 2017. Disponible en: <http://legal.legis.com.co/document/index?obra=j urcol\&document=jurcol_d19419719bf34f5a8863c69fdb4fb9oo >. [Fecha de consulta: 24 de mayo de 2018].

Tribunal Constitucional de España, Sentencia $N^{o} 116$ de 1999. Disponible en: <https:// www.iberley.es/jurisprudencia/sentencia-constitucional-n-116-1999-tc-plenorec-recurso-inconstitucionalidad-376-1989-17-06-1999-11997001?term=Reprodu cci\% $\mathrm{C}_{3} \% \mathrm{~B}_{3} \mathrm{n}+$ asistida + Filiaci\% $\mathrm{C}_{3} \% \mathrm{~B}_{3}$ \& \& query=Reproducci\% $\mathrm{C}_{3} \% \mathrm{~B}_{3} \mathrm{n}+$ asistida $+\mathrm{F}$ iliaci\%C3\%B3n\&noIndex>. [Fecha de consulta: 25 de mayo de 2018].

Tribunal Supremo de Justicia de Cataluña, Sala de lo Civil y Penal, Sentencia $N^{o}$ 28 de 27 de septiembre 2007. Disponible en: https://www.iberley.es/jurisprudencia/sentencia-civil-n-28-2007-tsj-cataluna-sala-civil-penal-sec-1-rec135-2006-27-09-2007-5733341? term $=$ Sentencia + Civil $+\mathrm{N} \% \mathrm{C}_{2} \% \mathrm{BA}+28 \% 2 \mathrm{~F} 2 \mathrm{O}$ $07 \% 2 \mathrm{C}+$ Tribunal + Superior $+\mathrm{de}+\mathrm{Justicia}+\mathrm{de}+\mathrm{Catalu} \% \mathrm{C}_{3} \% \mathrm{~B} 1 \mathrm{a}{ }_{2} \mathrm{C}+\mathrm{Sala}+\mathrm{de}+$ $\mathrm{lo}+\mathrm{Civil}+\mathrm{y}+$ Penal\% $2 \mathrm{C}+\mathrm{Secci} \% \mathrm{C}_{3} \% \mathrm{~B}_{3} \mathrm{n}+1 \%{ }_{2} \mathrm{C}+\mathrm{Rec}+135 \% 2 \mathrm{~F} 2 \mathrm{Oo} 6+\mathrm{de}+27+\mathrm{de}+$ Septiembre + de $+2007 \& q u e r y=S e n t e n c i a+C i v i l+N \% C_{2} \% B A+28 \% 2 F_{2007 \%} \mathrm{C}$ + Tribunal + Superior + de + Justicia + de + Catalu $\% C_{3} \%$ B1a $\% 2 C+S a l a+d e+l o+C i v i l$ $+\mathrm{y}+$ Penal ${ }_{2} \mathrm{C}+\mathrm{Secci} \% \mathrm{C}_{3} \% \mathrm{~B}_{3} \mathrm{n}+1 \% 2 \mathrm{C}+\mathrm{Rec}+135 \% 2 \mathrm{~F} 2006+\mathrm{de}+27+\mathrm{de}+$ Septiem bre + de $+2007 \&$ noIndex $>$ [Fecha de consulta: 23 de mayo de 2018]. 
Tribunal Supremo de Justicia de Cataluña, Sala de lo Civil y Penal, Sentencia $N^{o}$ 44 de 22 de diciembre de 20o8. Disponible en: <https://www.iberley.es/jurisprudencia/sentencia-civil-n-44-2008-tsj-cataluna-sala-civil-penal-sec-1-rec30-2007-22-12-2008-11565341?term=Reproducci\% $\mathrm{C}_{3} \% \mathrm{~B}_{3} \mathrm{n}+$ asistida +Filiaci\% $\mathrm{C}_{3} \%$ B3n\&query=Reproducci\% $\mathrm{C}_{3} \% \mathrm{~B}_{3} \mathrm{n}+$ asistida+Filiaci\% $\mathrm{C}_{3} \% \mathrm{~B}_{3}$ \&noIndex $>$. [Fecha de consulta: 23 de mayo de 2018].

Tribunal Supremo Popular de la República de Cuba, Sala de lo Civil y de lo Administrativo, Sentencia $N^{\circ} 862$ de 30 de diciembre de 2005, (recurso de casación). En Boletín del Tribunal Supremo Popular, La Habana, 2006.

Tribunal Supremo Popular de la República de Cuba, Sala de lo Civil y de lo Administrativo, Sentencia $N^{o} 249$ de 30 de junio de 2011, (recurso de casación). En Boletín del Tribunal Supremo Popular, La Habana, 2011.

Tribunal Supremo Popular de la República de Cuba, Sala de lo Civil y de lo Administrativo, Sentencia $N^{o} 510$ de 31 de octubre del 2013, (recurso de casación).

Tribunal Supremo Popular de la República de Cuba, Sala de lo Civil y de lo Administrativo, Sentencia $N^{\circ}$ Sentencia No. 895 de 23 de diciembre de 2014, (recurso de casación). 